\title{
Aged Translucent Aesthetic Zirconia: Bond Strength Analysis
}

\author{
Bernardo Luiz Gallina Mauro Carlos Agner Busato ${ }^{2}$ \\ Marcio Jose Mendonca' \\ ${ }^{1}$ Department of Prosthodontics, Western State University of \\ Paraná, Paraná, Brazil \\ 2Department of Orthodontics, Western State University of Paraná, \\ Paraná, Brazil \\ ${ }^{3}$ Department of Restorative Dentistry, Western State University of \\ Paraná, Paraná, Brazil
}

Eur J Dent 2019;13:5-10
Eliseu Augusto Sicoli ${ }^{1}$ Veridiana Camilotti ${ }^{3}$

\begin{abstract}
Address for correspondence Marcio Jose Mendonca, DDS, MS, PhD. Department of Prosthodontics, Western State University of Paraná, Paraná, Brazil (e-mail: dr.mendonca@uol.com.br).
\end{abstract}

\begin{abstract}
Keywords

- bond strength

- microshear

- zirconia

Objective This study evaluates the bond strength of two compositions of aesthetic translucent zirconia (TZ).

Materials and Methods For this evaluation, test specimens were prepared from ICE Zirkon TZ and Prettau Anterior zirconia (PAZ) that were stored in distilled water at $37^{\circ} \mathrm{C}$ for two time periods: $\mathrm{T} 1$ ( $24 \mathrm{~h}$ ) and T2 (90 days) to simulate aging. Two factors were evaluated for the samples-ceramic and aging time. The samples were subjected to tests of microshear strength and fracture type and were evaluated using scanning electron microscopy.

Results The results were analyzed using the D'Agostino test, analysis of variance, and Tukey's test $(p<0.01)$. Statistically significant differences were observed for ceramic type and aging time.

Conclusion The results showed that PAZ provides significantly superior performance to $\mathrm{TZ}$ at the two aging times evaluated.
\end{abstract}

\section{Introduction}

Zirconia-based ceramics are materials commonly used in indirect single-unit restorations, fixed partial dentures, indirect restorations, and, more recently, monolithic restorations. Zirconia has been extensively studied due to its biocompatibility, mechanical resistance, and aesthetic results, being widely used in dentistry. Several variations of zirconia have been developed, with each new material intended to provide some quality improvement over previous versions. Recently, the use of monolithic yttria-stabilized tetragonal zirconia polycrystal (Y-TZP) for indirect restorations has been developed to overcome the problems of veneered zirconia fixed dental prostheses (FDPs).

Monolithic zirconia FDPs are milled from blocks using computer-aided design/computer-aided manufacturing (CAD/CAM) equipment and can be used either polished or glazed for enhanced aesthetic outcomes. ${ }^{1,2}$ Monolithic zirconia FDPs have considerably enhanced strength and resistance to chipping. ${ }^{3}$ Different types of monolithic zirconia have been developed to obtain a more aesthetic and translucent restoration and to match zirconia's success in physical properties. ${ }^{4}$ Yttria $\left(\mathrm{Y}_{2} \mathrm{O}_{3}\right)$ is the most commonly utilized stabilizer. $^{5}$ The higher translucency of Y-TZP materials is achieved with much lower alumina content compared with conventional zirconia and an increase in $\mathrm{Y}_{2} \mathrm{O}_{3}$ content to minimize low-temperature degradation. ${ }^{6}$

In addition, it has been reported that the improved translucency of monolithic zirconia was attained by the combination of a relatively fine grain size and the presence of optically isotropic cubic zirconia particles that reduce grain-boundary light scattering. ${ }^{7}$ In spite of the advantages of monolithic zirconia restorations, bonding between adhesive resins and oxide ceramics still presents a challenge compared to that between adhesive resins and glassy matrix ceramics. ${ }^{18,9}$ Zirconia is silica free, which makes it difficult to etch.110,11 However, the greatest current challenge is to guarantee adequate bond strength with the resin cements used and to ensure satisfactory aesthetic results. 
There is no consensus on the best surface treatment to obtain optimum adhesive bond strength between zirconia and resin. Several methods have been suggested, including blasting with aluminum oxide, ${ }^{12-14}$ tribochemical reaction, ${ }^{12,15,16}$ laser irradiation, ${ }^{13,16-18}$ and even the combination of all these. ${ }^{14,16}$ Another way of increasing bond strength is to use monomers with phosphate in their composition. Furthermore, the combination of phosphate with aluminum blasting could be used. ${ }^{14}$

Resin cements are a good option for adhering parts, including zirconia, ${ }^{10}$ although, over time, this bond may lose strength, cause retention loss, and/or increase microleakage, primarily for two reasons: temperature variations, which cause differential contraction and dilation between materials, and moisture, which can cause cement dissolution and chemical degradation of the bond between zirconia and cement/adhesive. ${ }^{19}$ Therefore, aging in laboratory tests is important for simulating these conditions found in the oral environment, ${ }^{20}$ with high interference in the long term.

Another important point to take into account is the translucency of the material, given that, in a clinical setting, once the piece is positioned, the cement needs to be reached by light from the photoactivator to be activated. In this context, the cementation of highly opaque zirconia presents a challenge because those types are most susceptible to failure. ${ }^{16,21,22}$ Therefore, it is necessary to develop types of zirconia that are more translucent, allowing photoactivation by light through the element, and that can provide favorable aesthetics. A minimum energy density of $4000 \mathrm{~mJ} / \mathrm{cm}^{2}$ is required to ensure that the bond between dentin and adhesive is not affected. ${ }^{23}$ Prettau Anterior zirconia (PAZ) aims to combine the physical properties of zirconia with high translucency to meet the aesthetic needs of anterior teeth. In previous studies, PAZ showed greater light irradiation through different thicknesses, benefiting aesthetics, and cementation, when photoactivated cements were used.,24 Moreover, further studies are needed to evaluate the mechanical properties of this new material and to investigate whether these properties satisfy the minimum clinical and mechanical parameters.

Therefore, this study compared the microshear bond strength of two forms of aesthetic translucent zirconia (TZ): PAZ and ICE Zirkon TZ, both of which were previously aged.

\section{Materials and Methods}

The sample was calculated using a family $F$ probability, with a repeated families design, with interaction within and among the factors. The effect size of 0.15 , type $1(\alpha)$ error of 0.01 , and analysis power of 0.95 chosen resulted in 44 sample units (test specimens [TSs]), with 11 samples per experimental group. GPower software (version 3.1.9.2, University of Düsseldorf, Germany) was used for sample calculation.

The materials used in this study are listed in - Table $\mathbf{1 .}$ A total of 44 zirconia samples were produces, with 22 samples of $3 \mathrm{~mm} \times 5 \mathrm{~mm} \times 10 \mathrm{~mm}$ Zirkonzahn PAZ (Gais, Bolzano, Italy) in A1 color, through presintered blocks cut using a wet milling CAD/CAM machine (Zirkonzahn M1,
Table 1 List of the materials used

\begin{tabular}{|c|c|c|}
\hline Material & Manufacturer & Composition \\
\hline $\begin{array}{l}\text { Zirconia } \\
\text { Prettau } \\
\text { Anterior }\end{array}$ & $\begin{array}{l}\text { Zirkonzahn, } \\
\text { Gais, Bolza- } \\
\text { no, Italy }\end{array}$ & $\begin{array}{l}\mathrm{ZrO}_{2}, \mathrm{Y}_{2} \mathrm{O}_{3}<12 \%, \mathrm{Al}_{2} \mathrm{O}_{3}<1 \% \\
\mathrm{SiO}_{2}<0.02 \%, \mathrm{Fe}_{2} \mathrm{O}_{3}<0.01 \% \\
\mathrm{Na}_{2} \mathrm{O}<0.04 \%\end{array}$ \\
\hline $\begin{array}{l}\text { ICE Zirkon } \\
\text { Translucent } \\
\text { Zirconia } \\
\end{array}$ & $\begin{array}{l}\text { Zirkonzahn, } \\
\text { Gais, Bolza- } \\
\text { no, Italy }\end{array}$ & $\begin{array}{l}\mathrm{ZrO}_{2}, \mathrm{Y}_{2} \mathrm{O}_{3} 4-6 \%, \mathrm{Al}_{2} \mathrm{O}_{3}<1 \% \\
\mathrm{SiO}_{2}<0.02 \%, \mathrm{Fe}_{2} \mathrm{O}_{3}<0.01 \% \\
\mathrm{Na}_{2} \mathrm{O}<0.04 \%\end{array}$ \\
\hline $\begin{array}{l}\text { Monobond } \\
\text { Plus }\end{array}$ & $\begin{array}{l}\text { Ivoclar } \\
\text { Vivadent AG, } \\
\text { Liechtenstein }\end{array}$ & $\begin{array}{l}\text { Silane methacrylate, meth- } \\
\text { acrylate phosphate, meth- } \\
\text { acrylate, bisphenol glycidyl } \\
\text { methacrylate (Bis-GMA), and } \\
\text { triethylene glycol dimethacry- } \\
\text { late (TEG-DMA) }\end{array}$ \\
\hline $\begin{array}{l}\text { RelyX Uni- } \\
\text { cem U200 } \\
\text { Resin } \\
\text { Cement }\end{array}$ & $\begin{array}{l}\text { 3M ESPE } \\
\text { Dental, St. } \\
\text { Paul, MN, } \\
\text { USA }\end{array}$ & $\begin{array}{l}\text { Base: Methacrylate monomers, } \\
\text { methacrylate phosphoric acid, } \\
\text { silanized particles, initiator } \\
\text { components, stabilizer Cata- } \\
\text { lyst: Methacrylate monomers, } \\
\text { alkaline particles, initiator com- } \\
\text { ponents, silanized particles, } \\
\text { stabilizer, and pigments }\end{array}$ \\
\hline
\end{tabular}

Gais, Bolzano, Italy), and another 22 TZ samples (Zirkonzahn, Gais, Bolzano, Italy) in A1 color, measuring as much as PAZ, also presintered and cut in the CAD/CAM Zirkonzahn M1 Wet-Zirkonzahn milling machine (Zirkonzahn, Gais, Bolzano, Italy) at a final temperature of $1,500^{\circ} \mathrm{C}$ at a heating rate of $8^{\circ} \mathrm{C} / \mathrm{min}$ for $2 \mathrm{~h}$. The blocks were blasted over the entire surface using aluminum oxide of $100 \mu \mathrm{m}$ at 3.5 Bar for $5 \mathrm{~s}$. Forty-four circular PVC pipes (Tigre do Brasil S/A, Rio Claro, Brazil) of dimension $2 \mathrm{~cm} \times 5 \mathrm{~cm}$ were used to fix the blocks.

The zirconia block was placed on a glass plate within the tubes, and chemically activated acrylic resin Vip Flash (Dental Vip, Pirassununga, Brazil) was poured in sandy phase into the plastic tube until it was completely filled. Subsequently, all samples were cleaned with distilled water for $30 \mathrm{~s}$ and 37\% phosphoric acid (FGM, Florianópolis, Brazil) for $30 \mathrm{~s}$ to remove residues and then washed again with distilled water for $30 \mathrm{~s}$. Monobond Plus (Ivoclar Vivadent AG, Liechtenstein) was actively applied with a microbrush (Vigodent, Rio de Janeiro, Brazil) for $10 \mathrm{~s}$, and after $5 \mathrm{~min}$, cement with a matrix made of silicone by express addition (3M ESPE Dental, St Paul, Minnesota), measuring $1 \mathrm{~mm} \times$ $5 \mathrm{~mm} \times 10 \mathrm{~mm}$ and containing three cylindrical holes of 1-mm diameter ( - Fig. 1), was applied.

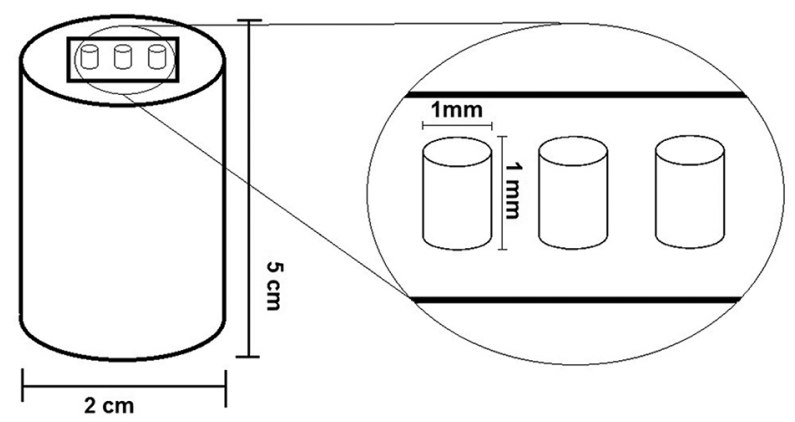

Fig. 1 Schematic representation of the experimental sample. 
The matrix was placed on the surface of the blocks for construction of the TSs used in the microshear strength test. Self-adhesive resin cement (RelyX Unicem U200; 3M ESPE Dental, St Paul, Minnesota) was handled as per the manufacturer's instructions and inserted into the silicone matrix. This was placed on the zirconia samples and overlaid with a polyester strip held under digital pressure by a previously trained operator for $5 \mathrm{~s}$; excess cement was removed.

Then, photoactivation was carried out for $20 \mathrm{~s}$ with Bluephase photopolymerizer (Ivoclar Vivadent AG, Liechtenstein) at a power of $1,200 \mathrm{~mW} / \mathrm{cm}^{2}$, directly on the polyester matrix; the matrices were removed. The photoactivator used was calibrated at every 10 uses to verify the intensity of the light supplied, using a radiometer (RD7; Ecel Indústria e Comércio Ltda, Ribeirão Preto, Brazil). The groups were divided into $11 \mathrm{TZ}$ samples (TZ1 group) and 11 PAZ samples (PAZ1 group), which were maintained in distilled water at $37^{\circ} \mathrm{C}$ for $24 \mathrm{~h}$. The remaining 11 TZ samples (TZ2 group) and 11 PAZ samples (PAZ2 group) were maintained for 90 days in distilled water at $37^{\circ} \mathrm{C}$.

The TSs underwent microshear bond strength test in a universal test machine (EMIC DL-200 MF; EMIC, São José dos Pinhais, Brazil). With a metallic wire (Morelli; Sorocaba, Brazil) with a diameter of $2 \mathrm{~mm}$ placed around the TS, the loading force was applied at the base of the TS at a traction speed of $0.5 \mathrm{~mm} / \mathrm{min}$ until fracture occurred ( - Fig. 2) ${ }^{25,26}$

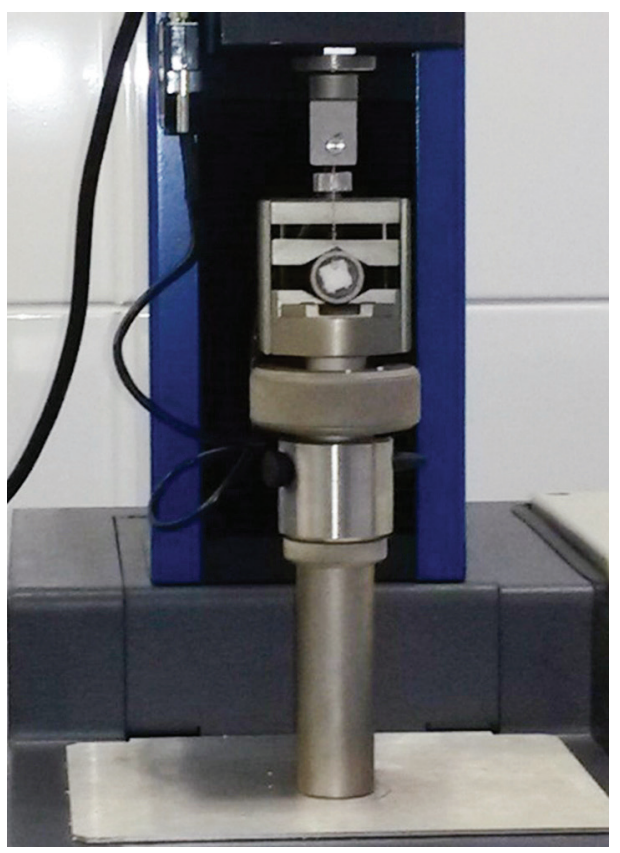

Fig. 2 Sample fixed to universal test machine.
The samples were analyzed using an Olympus SZX7 stereomicroscope (Tokyo, Japan) at $\times 7$ magnification. The fracture pattern was classified (by a single evaluator) in adhesive and mixed types.

Representative fractured beams from each group were desiccated, mounted in aluminum stubs, and sputter-coated with gold to analyze the morphology of the fracture patterns with a scanning electron microscope (SEM, JEOL-6390 LV, Tokyo, Japan).

The mean MPa data (arithmetic mean calculated from three values obtained from the same block) were analyzed using Bioestat 5.3 software (Instituto de Desenvolvimento Sustentável Mamirauá; Tefé, Brazil). For this, the values were initially subjected to the D'Agostino test. The data were found to be normally distributed and thus were subjected to factorial analysis of variance (ANOVA) and Tukey's post hoc test $(p<0.01)$.

\section{Results}

Factorial ANOVA of ceramic brand $x$ aging time showed statistically significant differences for both factors, but not for the interaction between them ( - Table 2 ).

The two types of material showed significantly different bond strength [MPa; - Fig. $\mathbf{3}$ and - Table 3], with the PAZ group showing the highest resistance to microshear after both $24 \mathrm{~h}$ and 90 days aging. The analysis of the same material showed a significant decrease after the storage period.

-Fig. 4 presents descriptive analysis of the fractures, with the PAS group displaying more mixed fractures than $\mathrm{TZ}$ at both aging times. In both materials, mixed fractures are reduced after 90 days.

-Figs. 5-8 show SEM analysis of the most representative samples from each experimental group.

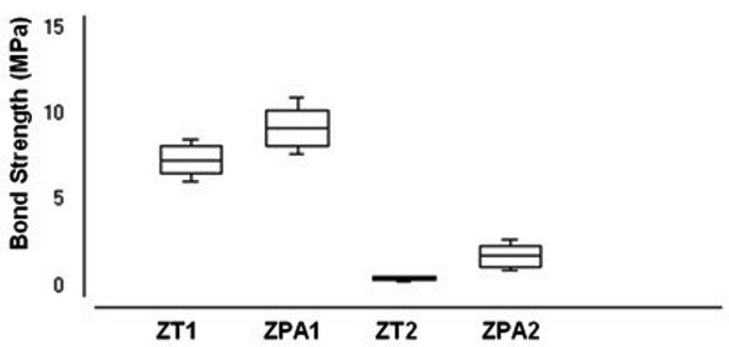

Fig. 3 Box-plot graph of the bond strength of the experimental groups (MPa).

Table 2 Factorial ANOVA for the experimental groups

\begin{tabular}{|l|l|l|l|l|l|}
\hline Sources of variation & Degrees of freedom & Sum of squares & Mean squares & Calculated F & Critical F \\
\hline Ceramic Brand & 1 & 30.2685 & 30.2685 & 47.107 & $<0.0001$ \\
\hline Time & 1 & 581.4255 & 581.4255 & 904.8773 & $<0.0001$ \\
\hline Interaction & 1 & 1.5252 & 1.5252 & 2.3737 & 0.1276 \\
\hline Error & 40 & 25.7018 & 0.6425 & & \\
\hline
\end{tabular}




\section{Discussion}

The PAZ samples showed significantly greater microshear bond strength compared to TZ samples, regardless of the immersion time. This is attributed to PAZ having higher yttrium oxide $\left(\mathrm{Y}_{2} \mathrm{O}_{3}\right)$ and hafnium oxide $\left(\mathrm{HfO}_{2}\right)$ contents (12\% of each) compared with $\mathrm{TZ}\left(6 \% \mathrm{Y}_{2} \mathrm{O}_{3}\right)$. This makes zirconia more stable, an important factor for maintaining the chemical

Table 3 Mean values of resistance to microshearing of the experimental groups, followed by the respective standard deviations (MPa) and statistical analysis

\begin{tabular}{|l|l|l|}
\hline Material/Time & 24 hours & 90 days \\
\hline ZT & $7.35( \pm 0.76)^{\text {Aa }}$ & $0.45( \pm 0.11)^{\mathrm{Ab}}$ \\
\hline ZPA & $9.16( \pm 1.03)^{\mathrm{Ba}}$ & $1.74( \pm 0.57)^{\mathrm{Bb}}$ \\
\hline
\end{tabular}

Different letters in the same row or column mean statistically significant differences. Capital letters for columns and lower case letters for rows $(p<0.01)$.

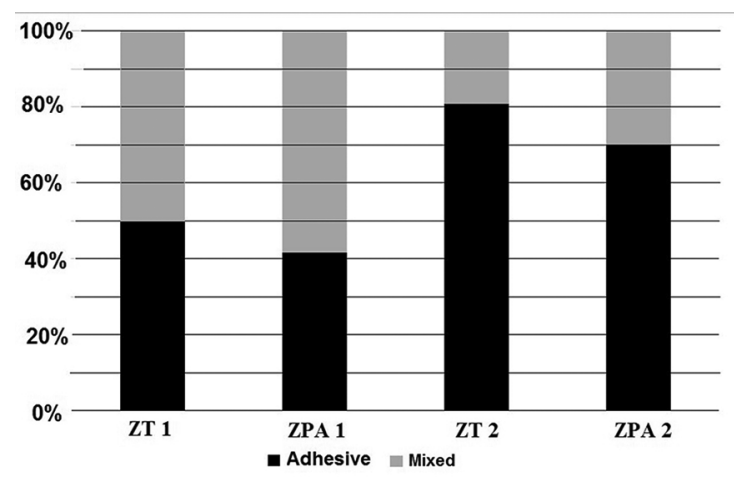

Fig. 4 Analysis of the frequency of fracture types (\%).

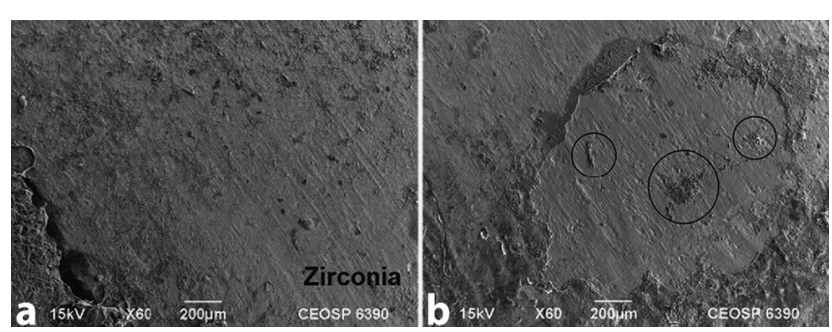

Fig. 5 Scanning electron micrograph of the ZT1 group. (a) Adhesive failure: It may be noted that no fragments of resin cement adhered to the surface of the zirconia. (b) Mixed failure: It is noted that cement adhered to the surface of the zirconia, as can be seen in the encircled areas.
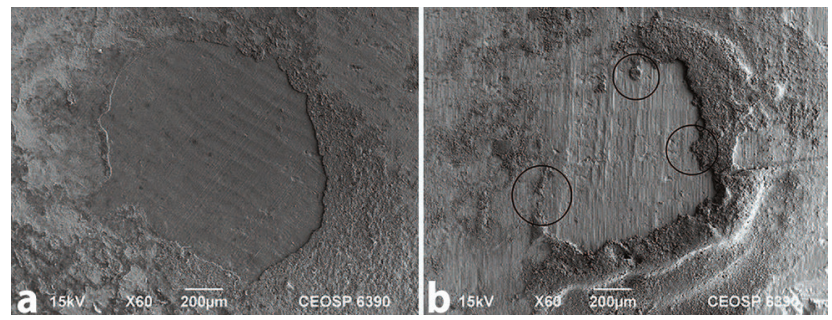

Fig. 6 Scanning electron micrograph of the ZPA1 group. (a) Adhesive failure: No fragments of resin cement adhered to the surface of the zirconia. (b) Mixed failure: It is noted on the surface of the zirconia resin cement adhered on the edges and part of the center of the surface where the cement post was located, as can be seen in the encircled areas.

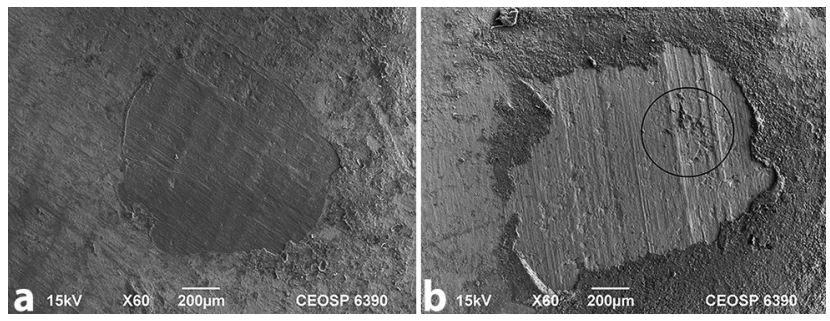

Fig. 7 Scanning electron micrograph of the ZT2 Group. (a) Adhesive failure: No resin cement adhered to the surface. (b) Mixed failure: There is a single area where resin cement is present in the encircled area.

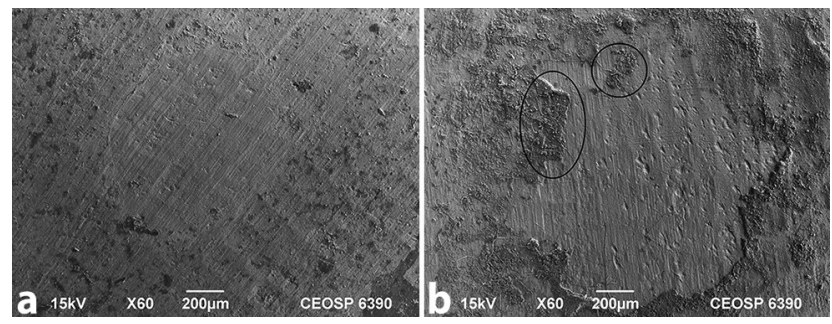

Fig. 8 Scanning electron micrograph of the ZPA2 group. (a) Adhesive failure: No resin is present on the surface, but some dirt appears. (b) Mixed failure: Areas are highlighted where resin can be observed after the microshear tests.

bonds between zirconia, adhesive, and cement, which might help ensure intact phosphate bonds in the long term. ${ }^{27}$

In the present study, the samples were aged by immersion in distilled water rather than by thermocycling, because a meta-analysis by Inokoshi et $\mathrm{al}^{28}$ observed a stronger correlation between storage failure at $100 \%$ humidity and stable temperature $(r=-0.4)$ than in thermocycling $(r=-0.15)$. When using thermocycling to simulate aging, large numbers of cycles $(100,000)$ have been suggested, so that a relevant effect can be found on the bonding surface, equivalent to approximately 3 months storage at $100 \%$ humidity, with similar results reported regarding the adhesion of enamel and dentine. ${ }^{29}$ Considering the amount of time required to complete so many thermocycles, and the equipment needed for the process, aging in distilled water proves to be of great value due to its positive results and easy applicability.

In addition to analyzing the bond strength, the samples were subjected to fracture type analysis. The reduction of mixed fractures after prolonged storage, as shown in - Fig. $\mathbf{3}$, probably occurred due to inherent degradation of resin cement and in the bond between the materials, directly affecting the results. Similar findings were observed in other studies that employed different forms of surface treatment. ${ }^{13,16}$ Cohesive fractures were not found but were reported in other studies that subjected zirconia to microshear tests. ${ }^{30}$

Various surface treatments aim to increase the surface roughness ${ }^{12,13,18}$ or the chemical bond between the components. ${ }^{12,14,16,31}$ However, greater surface roughness is necessary to increase the total bond area, a characteristic that is easy to achieve and use in the case of ceramic elements. ${ }^{28}$ Therefore, media blasting was used in this study. In addition, the application of adhesives containing monomers with methacryloyloxydecyl dihydrogen phosphate (MDP) increases the chemical 
bond between material and cement, ${ }^{32}$ becoming relevant in the choice of protocol employed. ${ }^{22}$ This type of treatment shows the best laboratory results ${ }^{28}$ and was therefore used here.

The SEM analysis revealed that a certain amount of resin cement remained adhered to the samples that suffered mixed failures. ${ }^{27}$ No resin cement was present on the surface of the zirconia in the adhesive fracture; so in these cases, the failure occurred at the zirconia/cement interface, suggesting that there was insufficient chemical bond between the materials. ${ }^{27}$ Comparing images between the different groups, there was no clear difference between the two materials at the same aging time. Comparison of the different aging times revealed more resin adhered in the zirconia in the samples that were aged for $24 \mathrm{~h}$, compared to those aged for 90 days. This is likely due to greater degradation of the interface between the materials with longer aging time.

The use of an in vitro protocol has limitations for predicting the behaviors of materials in vivo. Nevertheless, it was possible to observe superior mechanical behavior for PAZ than for TZ, which suggests the use of PAZ in the routine of dentistry practices, due to its superior aesthetics and mechanical resistance and due to the support technology involved in this type of oral rehabilitation, provided by materials, software, and the CAD/CAM system, providing aesthetic and mechanical predictability for PAZ crowns.

\section{Financial Support and Sponsorship}

None.

\section{Conflicts of Interest}

None.

\section{References}

1 Bavbek NC, Roulet JF, Ozcan M. Evaluation of microshear bond strength of orthodontic resin cement to monolithic zirconium oxide as a function of surface conditioning method. J Adhes Dent 2014;16(5):473-480

2 Stawarczyk B, Özcan M, Schmutz F, Trottmann A, Roos M, Hämmerle $\mathrm{CH}$. Two-body wear of monolithic, veneered and glazed zirconia and their corresponding enamel antagonists. Acta Odontol Scand 2013;71(1):102-112

3 Park JH, Park S, Lee K, Yun KD, Lim HP. Antagonist wear of three CAD/CAM anatomic contour zirconia ceramics. J Prosthet Dent 2014; 111(1):20-29

4 Sulaiman TA, Abdulmajeed AA, Donovan TE, et al. Optical properties and light irradiance of monolithic zirconia at variable thicknesses. Dent Mater 2015;31(10):1180-1187

5 Sulaiman TA, Abdulmajeed AA, Donovan TE, Vallittu PK, Närhi TO, Lassila LV. The effect of staining and vacuum sintering on optical and mechanical properties of partially and fully stabilized monolithic zirconia. Dent Mater J 2015; 34(5):605-610

6 Harada K, Raigrodski AJ, Chung KH, Flinn BD, Dogan S, Mancl LA. A comparative evaluation of the translucency of zirconias and lithium disilicate for monolithic restorations. J Prosthet Dent 2016;116(2):257-263

7 Zhang Y. Making yttria-stabilized tetragonal zirconia translucent. Dent Mater 2014;30(10):1195-1203

8 Aboushelib MN, Matinlinna JP, Salameh Z, Ounsi $H$. Innovations in bonding to zirconia-based materials: part I. Dent Mater 2008;24(9):1268-1272
9 Trakyali G, Malkondu O, Kazazoğlu E, Arun T. Effects of different silanes and acid concentrations on bond strength of brackets to porcelain surfaces. Eur J Orthod 2009;31(4):402-406

10 Bielen V, Inokoshi M, Munck JD, et al. Bonding effectiveness to differently sandblasted dental zirconia. J Adhes Dent 2015;17(3):235-242

11 Gomes AL, Castillo-Oyagüe R, Lynch CD, Montero J, Albaladejo A. Influence of sandblasting granulometry and resin cement composition on microtensile bond strength to zirconia ceramic for dental prosthetic frameworks. J Dent 2013;41(1):31-41

12 Elsaka SE. Influence of surface treatments on the bond strength of resin cements to monolithic zirconia. J Adhes Dent 2016;18(5):387-395

13 Foxton RM, Cavalcanti AN, Nakajima M, et al. Durability of resin cement bond to aluminium oxide and zirconia ceramics after air abrasion and laser treatment. J Prosthodont 2011;20(2):84-92

14 Tanış MÇ, Akçaboy C. Effects of different surface treatment methods and MDP monomer on resin cementation of zirconia ceramics an in vitro study. J Lasers Med Sci 2015;6(4):174-181

15 Wandscher VF, Fraga S, Pozzobon JL, et al. Tribochemical glass ceramic coating as a new approach for resin adhesion to zirconia. J Adhes Dent 2016;18(5):435-440

16 Gomes AL, Ramos JC, Santos-del Riego S, Montero J, Albaladejo A. Thermocycling effect on microshear bond strength to zirconia ceramic using Er:YAG and tribochemical silica coating as surface conditioning. Lasers Med Sci 2015;30(2):787-795

17 Paranhos MP, Burnett LH Jr, Magne P. Effect Of Nd:YAG laser and $\mathrm{CO}_{2}$ laser treatment on the resin bond strength to zirconia ceramic. Quintessence Int 2011;42(1):79-89

18 Gorler O, Ozdemir AK. Bonding strength of ceromer with direct laser sintered, $\mathrm{Ni}-\mathrm{Cr}$-based, and $\mathrm{ZrO}_{2}$ metal infrastructures after Er:YAG, Nd:YAG, and Ho:YAG laser surface treatments-a comparative in vitro study. Photomed Laser Surg 2016;34(8):355-362

19 Borba M, Miranda WG Jr, Cesar PF, Griggs JA, Bona AD. Evaluation of the adaptation of zirconia-based fixed partial dentures using micro-CT technology. Braz Oral Res 2013; 27(5):396-402

20 Attia A. Bond strength of three luting agents to zirconia ceramic-influence of surface treatment and thermocycling. J Appl Oral Sci 2011;19(4):388-395

21 Siqueira F, Cardenas AM, Gutierrez MF, et al. Laboratory performance of universal adhesive systems for luting CAD/ CAM restorative materials. J Adhes Dent 2016;18(4):331-340

22 Yavuz T, Dilber E, Kara HB, Tuncdemir AR, Ozturk AN. Effects of different surface treatments on shear bond strength in two different ceramic systems. Lasers Med Sci 2013;28(5):1233-1239

23 Hirai K, Tsujimoto A, Nojiri $K$, et al. Influence of photoirradiation conditions on dentin bond durability and interfacial characteristics of universal adhesives. Dent Mater J 2017;36(6):747-754

24 Sulaiman TA, Abdulmajeed AA, Donovan TE, et al. Degree of conversion of dual-polymerizing cements light polymerized through monolithic zirconia of different thicknesses and types. J Prosthet Dent 2015;114(1):103-108

25 Souza-Junior EJ, Borges BC, Montes MA, Alonso RC, Ambrosano GM, Sinhoreti MA. Influence of etching time and bonding strategies on the microshear bond strength of self- and light-cured pit-and-fissure sealants. Braz Dent J 2012;23(5):477-483

26 Lopes MB, Sinhoreti MA, Correr Sobrinho L, Consani S. Comparative study of the dental substrate used in shear bond strength tests. Pesqui Odontol Bras 2003;17(2):171-175 
27 Inokoshi M, Zhang F, Vanmeensel K, et al. Residual compressive surface stress increases the bending strength of dental zirconia. Dent Mater 2017;33(4):e147-e154

28 Inokoshi M, De Munck J, Minakuchi S, Van Meerbeek B. Meta-analysis of bonding effectiveness to zirconia ceramics. J Dent Res 2014;93(4):329-334

29 De Munck J, Mine A, Poitevin A, et al. Meta-analytical review of parameters involved in dentin bonding. J Dent Res 2012;91(4):351-357

30 Otani A, Amaral M, May LG, Cesar PF, Valandro LF. A critical evaluation of bond strength tests for the assessment of bonding to Y-TZP. Dent Mater 2015;31(6):648-656
31 Martins AR, Gotti VB, Shimano MM, Borges GA, Gonçalves LdeS. Improving adhesion between luting cement and zirconia-based ceramic with an alternative surface treatment. Braz Oral Res 2015;29:54

32 Noda Y, Nakajima M, Takahashi M, et al. The effect of five kinds of surface treatment agents on the bond strength to various ceramics with thermocycle aging. Dent Mater J 2017;36(6):755-761 